\title{
Load frequency control of an asynchronous restructured power system: a fuzzy logic approach
}

\author{
S.K. Pandey ${ }^{1}$, S.P. Singh ${ }^{2}$, and Vinay Pratap Singh $^{3}$ \\ ${ }^{1 *}$ Department of Electrical Engineering, Motilal Nehru National Institute of Technology, Allahabad, INDIA \\ ${ }^{2}$ Department of Electrical Engineering, Kamla Nehru Institute of Technology, Sultanpur, INDIA \\ ${ }^{3}$ Department of Electrical Engineering, Motilal Nehru National Institute of Technology, Allahabad, INDIA \\ "Corresponding Author: e-mail: skp1111.1969@rediffmail.com, Mob. +91-9453464669
}

\begin{abstract}
This paper presents the analysis of load frequency control (LFC) of a two-area restructured power system interconnected via parallel ac/dc transmission links. Simulation results show that the limitations of PI controller can be overcome by including Fuzzy logic concept and thereby the dynamic performance can be improved substantially following a load change in any area. The dynamic responses for small perturbation have been observed with PI controller and fuzzy logic based PI controller and result of both have been compared.
\end{abstract}

Keywords: Asynchronous tie-lines; Restructured power system; HVDC transmission links; Load frequency control; Fuzzy Logic based PI controller.

DOI: http://dx.doi.org/10.4314/ijest.v4i1.3S

\section{Introduction}

In power system the active power has to be generated as the same time it is consumed. Any mismatch between the generated power and the demanded power leads to power imbalance causes the system frequency and the tie line power to deviate from their nominal and scheduled values [Ewart et al. 1992]. These mismatches are corrected by controlling, which is defined as the regulation of the power output of generators within a prescribed area. The basic role of LFC is to maintain the megawatt output of a generator in balance with the demand and therefore control the interconnected frequency [Elgered et al. 1970]. Many controllers have been presented for power system LFC problems in order to obtain a better dynamic performance, where the most employed one is the conventional fixed gain controller like a proportional integral (PI) controller or a PID controller. Fixed gain controllers are designed at nominal operating points by try and error and may no longer be suitable in all operating conditions. For this reason fuzzy logic based PI controller has been proposed for LFC. A little attention has been paid to use of HVDC transmission link as system interconnection and a favorable effect on system dynamic performance has been achieved considering such system interconnection [Mahadavi et al. 2008 and Manjunath et al. 2007].

Under restructured (deregulation) the power system structure changed in such a way that would allow the evolving of more specialized industries for generation (Genco), transmission (Transco) and distribution (Disco).In the restructured power system, DISCOs in each area can contract with GENCOs in its or other areas[Ewart et al. 1992], [Donde et al. 2001]. As there are several Gencos and Discos in the restructured power system, a Disco has the freedom to have a contract with any Genco for transaction of power. A Disco may have a contract with a Genco in another control area. Such transactions are called "bilateral transactions." All the transactions have to be cleared through an impartial entity called an independent system operator (ISO). The ISO has to control a number of so-called "ancillary services" one of which is load frequency control. This paper is devoted to analyze the dynamic performance of two interconnected thermal units when equipped with HVDC transmission link parallel to AC tie line under 
restructured environment. A fuzzy logic controller is designed to facilitate the operation smooth and less oscillatory when system is subjected to a sudden load change.

\section{Restructured Power System}

In the restructured power system, GENCOs sell power to various DISCOs at competitive prices. Thus, DISCOs have the freedom to choose the GENCOs for contracts. They may or may not have contracts with the GENCOs in their own area. There can be various combinations of contracts between DISCOs and GENCOs which can be conveniently visualized by the concept of a 'DISCO participation matrix' (DPM). The rows of a DPM correspond to GENCOs and columns to DISCOs which contract power. Each entry in this matrix can be thought as a fraction of a total load contracted by a DISCO (column) towards a GENCO (row). The sum of all the entries in a column in this matrix is unity. Consider a two-area power system in which each area has two GENCOs and two DISCOs in it. Let GENCO $, \mathrm{GENCO}_{2}, \mathrm{DISCO}_{1}$, and $\mathrm{DISCO}_{2}$ be in areal and $\mathrm{GENCO}_{3}, \mathrm{GENCO}_{4}, \mathrm{DISCO}_{3}$, and $\mathrm{DISCO}_{4}$ be in area 2 as shown in Figure 1 [Mahadavi et al. 2008].

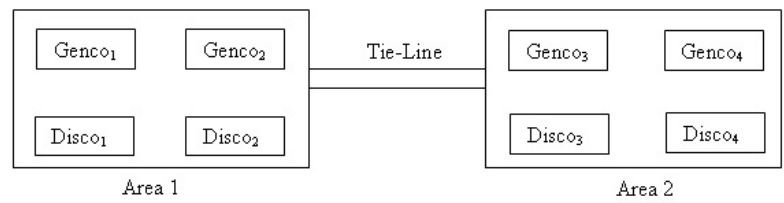

Figure 1. Block Diagram of two area restructured power system

The corresponding DPM for a two-area power system will have the structure that follows:

$$
\left[\begin{array}{llll}
c p f_{11} & c p f_{12} & c p f_{13} & c p f_{14} \\
c p f_{21} & c p f_{22} & c p f_{23} & c p f_{24} \\
c p f_{31} & c p f_{32} & c p f_{33} & c p f_{34} \\
c p f_{41} & c p f_{42} & c p f_{43} & c p f_{44}
\end{array}\right]
$$

Where $\mathrm{cpf}_{\mathrm{jd}}=$ Contract Participation factor of $\mathrm{j}^{\text {th }}$ GENCO in the load following of $\mathrm{d}^{\text {th }}$ DISCO. DPM shows the participation of a DISCO in a contract with any GENCO, hence the name Disco Participation Matrix. The diagonal element of DPM represents the local demand and off diagonal element represents the demand of the DISCOs in one area to the GENCOs in another area.

\section{Two Area Power System Model}

The two area power system model used in this paper is a two-area restructured interconnected system consisting of identical thermal power plants. The two-areas are interconnected via AC tie-line in parallel with HVDC link. The single line diagram of power system model under consideration is shown in Figure 2 [Mahadavi et al. 2008 and Manjunath et al. 2007]. The transmission links are considered as long transmission lines specifically of length greater than break even distance length of AC and HVDC transmission lines. The distance normally used as break even distance is about $600 \mathrm{~km}$.

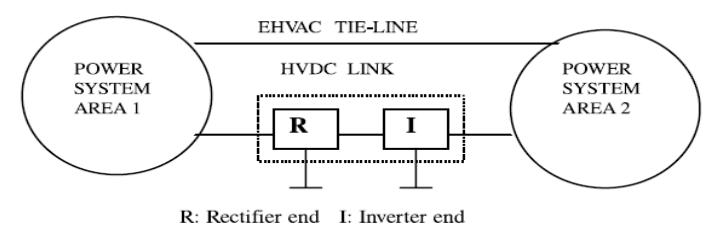

Figure 2. Two area power system with parallel AC/HVDC links

\section{Fuzzy Logic Controller}

Fuzzy set theory and fuzzy logic establish the rules of a non-linear mapping. Fuzzy control is based on a logical system called fuzzy logic which is much closer in spirit to human thinking and natural language than classical logical systems. The Fuzzy Logic Controller is based on fuzzy logic and provides an algorithm, which can convert the linguistic control strategy based on expert knowledge in to an automatic control strategy. The fuzzy logic controller consist mainly four components: (a) fuzzifier, (b) inference engine, (c) rule base, and (d) defuzzifier, as shown in Figure 3 (a). The Fuzzifier transforms the numeric into fuzzy sets, called fuzzification. The main purpose of the fuzzy logic controller is the inference engine, which performs all logic manipulations in a fuzzy logic controller. The rule base consists of membership functions and control rules. The output of the inference process is 
represented by a fuzzy set; however, the output of the fuzzy logic controller should be a numeric value. So, fuzzy set is transformed into a numeric value by defuzzifier, called defuzzification.

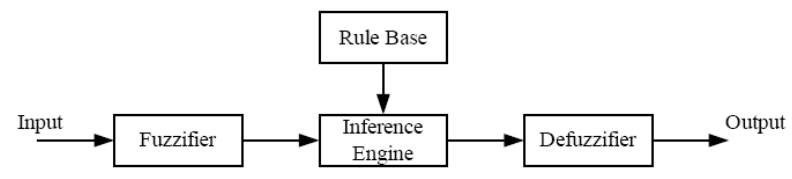

Figure 3(a). Components of Fuzzy logic controller

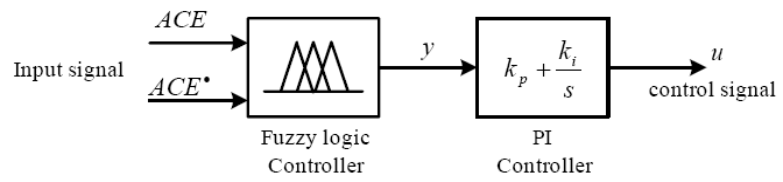

Figure 3(b). Fuzzy logic based PI controller

The basic structure of the fuzzy logic based PI controller used in this paper is as shown in Figure 3 (b), the control signal is given by

$$
\mathrm{u}=-\left(\mathrm{K}_{\mathrm{p}} \mathrm{y}+\mathrm{K}_{\mathrm{i}} \int \mathrm{ydt}\right)
$$

Where $\mathrm{K}_{\mathrm{p}}$ and $\mathrm{K}_{\mathrm{i}}$ are the proportional and integral gains respectively and $\mathrm{y}$ is the error signal. Differentiate above equation w.r.t. time then, we get

$$
\mathrm{du} / \mathrm{dt}=-\left(\mathrm{K}_{\mathrm{p}} \mathrm{dy} / \mathrm{dt}+\mathrm{K}_{\mathrm{i}} \mathrm{y}\right)
$$

The inputs to the fuzzy logic controller for load frequency for $\mathrm{i}^{\text {th }}$ area are ACE (area control error) and change in area control error i.e. $\mathrm{ACE}^{*}$ and output of the fuzzy controller is $\Delta \mathrm{u}$. The inputs and outputs are transformed to seven linguistic variables LN, MN, SN, Z, SP, MP and LP which stand for Large Negative, Medium Negative, Small Negative, Zero, Small Positive, Medium Positive and Large Positive respectively. Symmetrical triangular (expect of the two outermost ones which have a trapezoidal shape) membership function is considered here for all the three variables of $\mathrm{ACE}, \mathrm{ACE}^{*}$ and $\Delta \mathrm{u}$ of range -1 to +1 as shown in Figure 3 (c) [Donde et al. 2001, Ngamroo et al. 2006, Cam et al. 2005, and Al-Basri et al. 1999]. This range has been divided into control areas by membership functions that are triangular or trapezoidal.
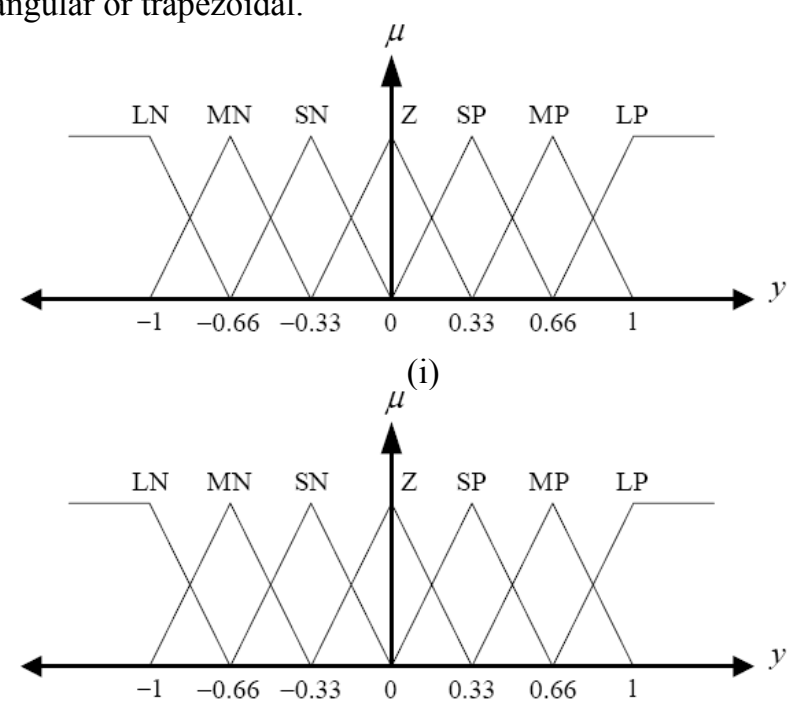

(ii)

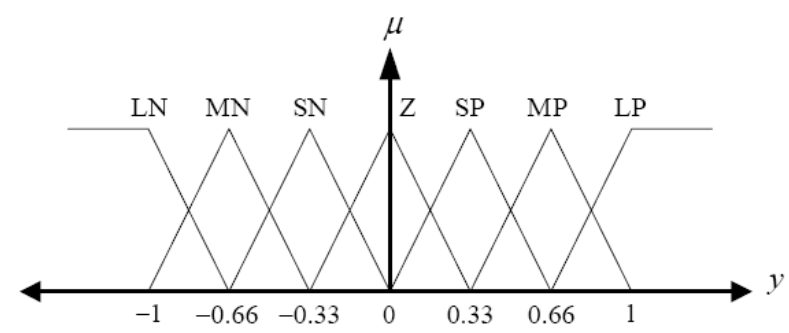

(iii)

Figure 3(c). Membership functions for fuzzy logic based PI controller (i) For input 1: ACE, (ii) For input 2: ACE ${ }^{*}$, (iii) For output. 
Framing of the control rules are more complicated, which depend on the designer experiences and actual physical system. As each of the three fuzzy variables are quantized to seven fuzzy sets, so total $7 \times 7$ or 49 rules are required to generate an fuzzy output relating two input fuzzy sets as shown in Table 1. The control rules build from the if-then statement. Table 1 is presenting the rules for fuzzy logic controller under study [Donde et al. 2001, Ngamroo et al. 2006, Cam et al. 2005, and Al-Basri et al. 1999]. Mamdani fuzzy theory is applied in determining the gain of controller.

Table 1. The control rules for fuzzy logic PI controller

\begin{tabular}{|c|c|c|c|c|c|c|c|}
\hline & & \multicolumn{6}{|c|}{$A C E^{\circ}$} \\
\hline & LN & $\mathrm{MN}$ & SN & Z & SP & MP & LP \\
\hline LN & $L P$ & $L P$ & $L P$ & $M P$ & $M P$ & $S P$ & $Z$ \\
\hline $\mathrm{MN}$ & $L P$ & $M P$ & $M P$ & $M P$ & $S P$ & $Z$ & $S N$ \\
\hline SN & $L P$ & $M P$ & $S P$ & $S P$ & $Z$ & $S N$ & $M N$ \\
\hline Z & $M P$ & $M P$ & $S P$ & $Z$ & $S N$ & $M N$ & $M N$ \\
\hline SP & $M P$ & $S P$ & $Z$ & $S N$ & $S N$ & $M N$ & $L N$ \\
\hline MP & $S P$ & $Z$ & $S N$ & $M N$ & $M N$ & $M N$ & $L N$ \\
\hline LP & Z & $S N$ & $M N$ & $M N$ & $L N$ & $L N$ & $L N$ \\
\hline
\end{tabular}

\section{Simulation Results of a Restructured two area asynchronous Power System}

In this paper, a fuzzy logic based PI controller has been applied to a restructured asynchronous two area power system. The values of system parameters are given in appendix.

5.1 Case 1 Base case: Consider a case where the GENCOs in each area participate equally in AGC, i.e. ACE participation factors are apf1 $=0.5$, apf2 $=1-$ apf $1=0.5 ;$ apf3 $=0.5$, apf $4=1-\operatorname{apf3}=0.5$.

Assume that the load change occurs only in area 1. Thus, the load is demanded only by DISCO1 and DISCO2. Let the value of this load perturbation be 0.1 p.u. MW for each of them [Mahadavi et al. 2008].

$$
\mathrm{DPM}=\left[\begin{array}{cccc}
0.5 & 0.5 & 0 & 0 \\
0.5 & 0.5 & 0 & 0 \\
0 & 0 & 0 & 0 \\
0 & 0 & 0 & 0
\end{array}\right]
$$

Note that as DISCO3 and DISCO4 do not demand from any GENCOs, corresponding participation factors (columns 3 and 4) are zero. DISCO1 and DISCO2 demand identically from their local GENCOs viz. GENCO1 and GENCO2. The frequency deviations in area 1 and 2 and tie line power flow following a step change in the loads of DISCO1 and DISCO2 are as shown in Figure 4(A), 4(B) and 4(C) respectively.

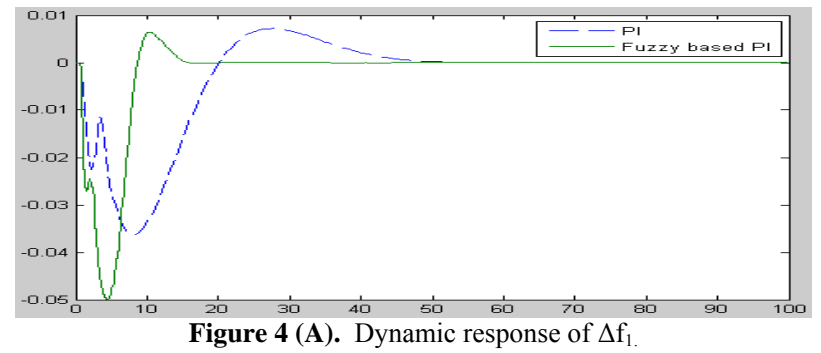

Figure 4 (A). Dynamic response of $\Delta \mathrm{f}_{1}$ 


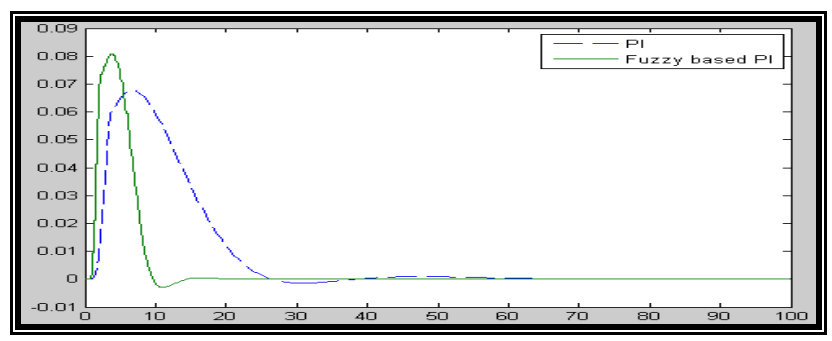

Figure 4 (B). Dynamic response of $\Delta \mathrm{f}_{2}$.

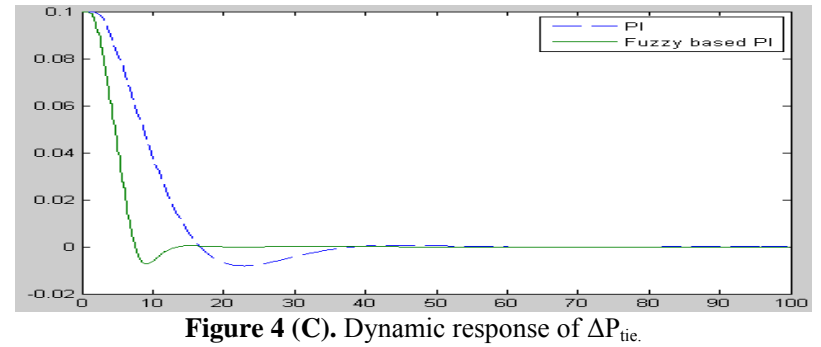

5.2 Case 2: Consider a case where all the DISCOs contract with the GENCOs for power as per the following DPM:

$\left[\begin{array}{cccc}0.5 & 0.25 & 0 & 0.3 \\ 0.2 & 0.25 & 0 & 0 \\ 0 & 0.25 & 1 & 0.7 \\ 0.3 & 0.25 & 0 & 0\end{array}\right]$

Assume that the total load of each DISCO is perturbed by $0.1 \mathrm{pu}$ and each GENCO participates in AGC as defined by following apfs: $a f_{1}=0.75, a p f_{2}=1-a p f_{1}=0.25 ; \operatorname{apf}_{3}=0.5, a p f_{4}=1-a p f_{3}=0.5$ [Mahadavi et al. 2008]. The dynamic responses in this case are as shown in Figure 5(A)-5(C).

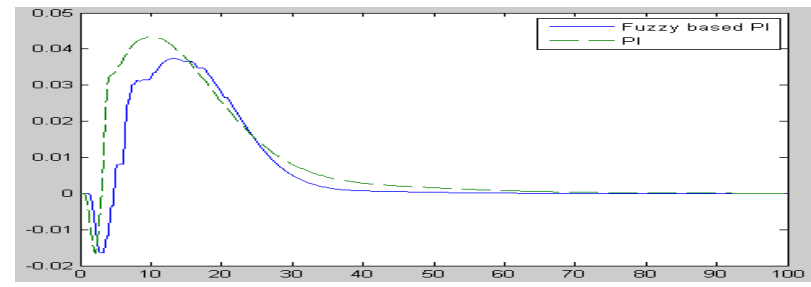

Figure 5 (A). Dynamic response of $\Delta \mathrm{f}_{1}$

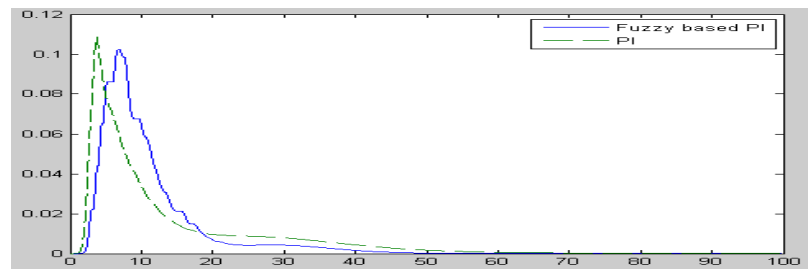

Figure 5 (B). Dynamic response of $\Delta \mathrm{f}_{2}$.

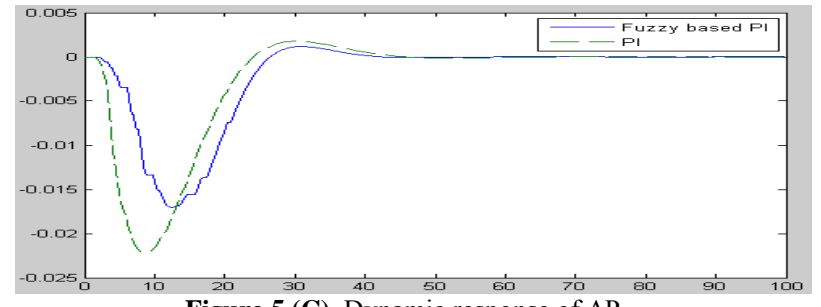

Figure $5(C)$. Dynamic response of $\Delta \mathrm{P}_{\text {tie. }}$. 
5. 3 Case 3 Contract Violation: Consider case 2 again except that DISCO 1 demands an additional 0.1 p.u. MW which is not contracted out to any GENCO. The uncontracted load of DISCO 1 reflects in the generations of GENCO 1 and GENCO 2 . Thus, this excess load is taken up by the GENCOs in the same area as that of the DISCO making the un-contracted demand [Mahadavi et al. 2008]. The dynamic responses in this case are as shown in Figure 6(A)-6(C).

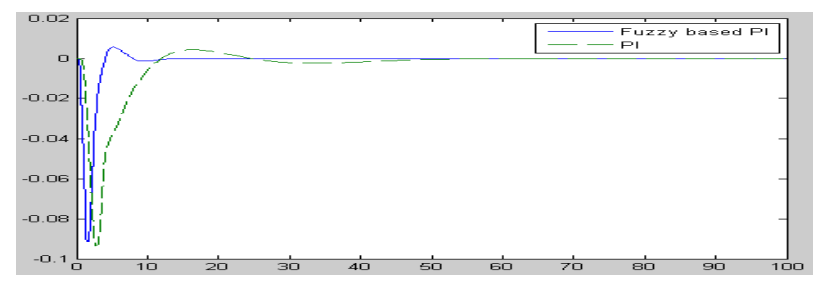

Figure 6 (A). Dynamic response of $\Delta \mathrm{f}_{1}$

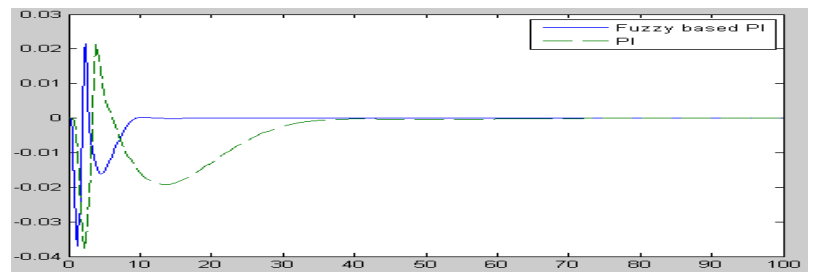

Figure 6 (B). Dynamic response of $\Delta \mathrm{f}_{2}$

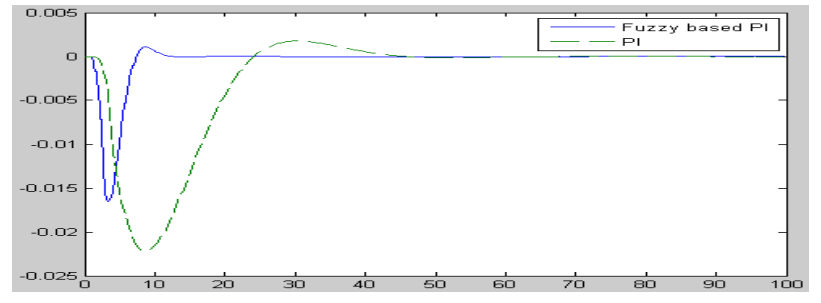

Figure 6 (C). Dynamic response of $\Delta \mathrm{P}_{\text {tie. }}$

\section{Conclusion}

This paper has investigated the dynamic performance of conventional PI controller and Fuzzy logic based PI controller on a restructured asynchronous thermal power system. The simulation results showed that the performance of the proposed fuzzy logic based controller is superior to conventional PI controller in terms of overshoot and settling time.

\section{Appendix}

All the notations carry the usual meanings.

System Data: $\mathrm{P}_{\mathrm{r} 1}=\mathrm{P}_{\mathrm{r} 2}=$ Rated area capacities $=1200 \mathrm{MW}$

$\mathrm{T}_{\mathrm{g} 1}=\mathrm{T}_{\mathrm{g} 2}=$ Governor Time constant of thermal area $=0.08 \mathrm{~s}$

$\mathrm{K}_{\mathrm{g} 1}=\mathrm{K}_{\mathrm{g} 2}=$ Governor Gain constant $=1.0$

$\mathrm{T}_{\mathrm{t} 1}=\mathrm{Tt}_{2}=$ Turbine time constant $=0.3 \mathrm{~s}$

$\mathrm{K}_{\mathrm{t} 1}=\mathrm{K}_{\mathrm{t} 2}=$ Turbine gain constant $=1.0$

$\mathrm{T}_{\mathrm{p} 1}=\mathrm{T}_{\mathrm{p} 2}=$ Power system time constants $=20 \mathrm{~s}$

$\mathrm{K}_{\mathrm{p} 1}=\mathrm{Kp}_{2}=$ Power system Gains $=120 \mathrm{~Hz} /$ p.u. $\mathrm{MW}$

$\mathrm{R}_{1}=\mathrm{R}_{2}=$ Governor Speed regulation parameter $=2.4 \mathrm{~Hz} /$ p.u. $\mathrm{MW}$

$\mathrm{B}_{1}=\mathrm{B}_{2}=$ Frequency bias constants $=0.425 \mathrm{p} . \mathrm{u}$. $\mathrm{MW} / \mathrm{Hz}$

$\mathrm{T}_{12}=$ Synchronizing coefficient $=0.0868 \mathrm{~s}$

Data for ac and dc Links: $\mathrm{K}_{\mathrm{dc}}=$ Gain associated with dc link=1.0

$\mathrm{T}_{\mathrm{dc}}=$ Time constant of $\mathrm{dc}$ link $=0.2 \mathrm{~s}$

Controller Gains: (i) For PI controller: $\mathrm{K}_{\mathrm{P}}=1.0, \mathrm{~K}_{\mathrm{I}}=0.4, \mathrm{~K}_{\mathrm{D}}=0.0$. (ii) For fuzzy base PI controller: $\mathrm{K}_{\mathrm{P}}=1.0879, \mathrm{~K}_{\mathrm{l}}=0.489, \mathrm{~K}_{\mathrm{D}}=0.0$. 


\section{References}

Al-Basri Fadel, and Talaq Jawad 1999 Adaptive Fuzzy Gain Scheduling for Load Frequency Control, IEEE Transactions on Power Systems, vol.14, No.1.

Cam Ertugrul and Kocaarslan Ilhan 2005 Load Frequency Control in two area power systems using fuzzy logic controller, Energy Conversion and Management 46 (2005) 233-243.

Donde Vaibhav, Hiskens Ian A., and Pai M. A. 2001, Simulation and Optimization in an AGC system after deregulation, IEEE trans. On power systems, Vol. 16, No. 3.

Elgered O. I. and Fosha C. 1970 Optimum megawatt-frequency control of multiarea electric energy systems, IEEE trans. Power Apparatus \& system, vol. PAS-89, No. 4, pp. 556-563.

Ewart D.N., Fink L.H., and Jaleel N. 1992 Understanding automatic generation control, IEEE Trans. on Power Systems, Vol.7, No.3, pp.1106-1122.

Mahadavi, S. Naghizadeh, Z., and Rao, C. Srinivasa 2008 Improvement of dynamic performance of hydrothermal system under open market scenario using asynchronous tie-lines, World Jorn. Of modeling and Simulation, Vol. 4, No. 2, pp 153-160.

Manjunath, H. V. and Mathur H. D. 2007, Study of dynamic performance of thermal units with asynchronous tie-liens using Fuzzy based controller, J. Electrical systems 3-3(2007): 124-130.

Ngamroo Issarachai, Pothiya Saravuth, Runggeratigul Suwan, and Tantaswadi Prinya, 2006 Design of Optimal Fuzzy Logic based controller using Multiple Tabu Search Algorithm for Load Frequency Control, International Journal of Control, Automation, and Systems, Vol.4, No.2, pp.155-164.

Biographical notes

S.K. Pandey is with the Department of Electrical Engineering, Motilal Nehru National Institute of Technology, Allahabad, INDIA

S.P. Singh is with the Department of Electrical Engineering, Kamla Nehru Institute of Technology, Sultanpur, INDIA

Vinay Pratap Singh is with the Department of Electrical Engineering, Motilal Nehru National Institute of Technology, Allahabad, INDIA

Received January 2012

Accepted February 2012

Final acceptance in revised form March 2012 